\title{
The Influence of Logistics Mode on Cross Border E-commerce Business Scale
}

\author{
Hu Xiaohui ${ }^{1}$ \\ ${ }^{1}$ School of Economics and Management, Beijing Jiaotong University, Beijing, China
}

\begin{abstract}
China's cross-border e-commerce companies are facing the problem of high logistics cost caused by excessive reliance on road transportation in domestic logistics link. In the long-term development, crossborder e-commerce companies in the United States have adopted the intermodal transportation logistics mode, which can reduced the domestic logistics costs. In order to study the impact of intermodal-transportation logistics mode on the scale of cross-border e-commerce companies, this paper selects the relevant data of Hub Group, the first intermodal marketing company in North America, makes multiple regression analysis, and draws the following conclusion: the intermodal-transportation logistics mode of highway and railway collaborative transportation is conducive to the expansion of cross-border e-commerce business scale.
\end{abstract}

\section{Introduction}

Since 2013, China's cross-border e-commerce has achieved rapid development. While the business scale of China's cross-border e-commerce continues to expand, it also faces the problems brought by logistics problems. Some scholars pointed out that the logistics cost of international cross-border e-commerce accounts for 30-40\% of the total cost, but the logistics cost of China's crossborder e-commerce is higher than this level [1]. The reason is that China's cross-border e-commerce starts late, lacks professional third-party logistics to provide services for it, and has not formed a mature cross-border e-commerce logistics mode. However, the reason why the domestic logistics cost is very high is that the logistics link in China still mainly relies on road transportation, while the labor cost, fuel cost and other indirect cost caused by accidents and pollution of road transportation is relatively high, which eventually leads to the logistics cost problem of China's cross-border e-commerce.

Cross border e-commerce started earlier in the United States and some cross-border e-commerce companies have gradually formed a mature logistics mode in the long-term development. Especially in the domestic logistics link of the United States, the third party logistics company and the railway company cooperate to deliver the long-distance transportation part of the goods to the railway company, while the short-distance part is still carried by the truck company. Through intermodal transportation, it provides professional logistics services for many cross-border ecommerce companies. At the same time, it also saves the domestic logistics transportation cost and improves the domestic logistics transportation efficiency. The domestic logistics of cross-border e-commerce in the United States relies on intermodal transportation, which is different from the mode that China relies on road transportation. Therefore, studying whether the logistics mode will significantly affect the increase of cross-border ecommerce business scale can help to solve the logistics problems of China's cross-border e-commerce.

\section{Literature Review}

Whether it is e-commerce or cross-border e-commerce, the existing researches generally affirmed the key guarantee and promotion role of logistics. Some scholars pointed out in the research on the development status of international express industry that the development of cross-border ecommerce promotes the development of express industry; the development of express industry promotes the development of global international trade; international express enterprises of various countries promote the development of international express delivery and crossborder E-commerce while seeking efficiency and fairness [2]. Some scholars fully affirmed the role of express logistics industry in promoting the development of ecommerce, and pointed out that e-commerce and express logistics industry should develop together [3]. Some scholars pointed out that in the e-commerce environment, enterprises should accelerate the transformation of logistics organizational structure, strengthen the training of logistics management personnel, and promote logistics management innovation to meet the growing demand of ecommerce logistics [4]. Some scholars pointed out that since cross-border e-commerce is still in the early stage of development in China, cross-border e-commerce and cross-border logistics are still emerging things, and the development of cross-border logistics is slower than that of cross-border e-commerce, which hinders the vigorous development of cross-border e-commerce, and the coordinated development of world War II should be 
realized [5]. Some scholars pointed out that the lack of coordination and unity among various links of domestic cross-border logistics internal industrial chain hindered the development of cross-border e-commerce, and introduced the advanced experience of foreign cross-border ecommerce logistics mode [6]. Other scholars pointed out that the level of synergy between cross-border e-commerce and cross-border logistics directly affects the operation efficiency of the entire cross-border e-commerce ecosystem. Therefore, promoting the coordinated development of the two and solving the dilemma of lack of coordination has become an urgent problem to be solved in the practical development and theoretical Research of cross-border e-commerce and cross-border logistics [7].

According to the existing researches, a large number of them have focused on the problem of logistics mode in cross-border e-commerce, and have also recognized that the objective problems of logistics mode hinder the development of cross-border e-commerce. That is to say, solving the problem of logistics mode will help to promote the development of cross-border e-commerce. However, few studies have focused on the cost of domestic logistics mode of cross-border e-commerce, and most of the research on logistics mode is qualitative, lacking of sufficient quantitative analysis. Therefore, this paper will start with the cost of domestic logistics link of cross-border e-commerce logistics mode, and use the empirical research method of quantitative analysis to study the impact of logistics mode on the business scale of cross-border ecommerce.

\section{Model Settings And Variables Description}

\subsection{Model Setting And Basic Assumptions}

Hub Group Company (abbreviated to "Hub", for short) of the United States is the first intermodal marketing company in North America. In 2005, the company sought cooperation with Union Pacific Company (abbreviated to "UP", for short), a railway company, and completed the transformation of its logistics mode [8]. After that, the indicators related to the domestic logistics cost of crossborder e-commerce, such as fuel cost, labor cost, transportation safety and transportation timeliness, have been improved, and the business scale of cross-border ecommerce has also expanded. It is worth noting that after 2005 , the number of 53-feet intermodal containers owned by Hub has rapidly increased from 0 to more than 30000 in 2018. From a practical point of view, the purpose of Hub to increase the number of containers is to improve the turnover rate of containers in domestic logistics link and avoid the problem of insufficient transportation capacity and additional container leasing expenses. Theoretically, some scholars pointed out that the increase of specific assets is an important prerequisite for the formation of contractual relationship between the two parties of market transactions [9]. Here, the increase of Hub's intermodal transport containers can also be considered as a way to consolidate the contractual relationship under the logistics mode of cooperation with railway companies.
Based on the above analysis, this paper takes the business scale of Hub's cross-border e-commerce customers as the dependent variable, and takes the special assets of Hub, fuel cost, transportation safety, labor cost, and transportation timeliness as independent variables, and establishes the following multivariate regression model:

$\Delta i n c=\beta_{0}+\beta_{1} \Delta c o n+\beta_{2} \Delta f r+\beta_{3} \Delta a r+\beta_{4} \Delta t r+$ $\beta_{5} \Delta f c+u_{t}$

According to this model, this paper puts forward five basic hypotheses: (a) the business scale of cross-border ecommerce is positively correlated with the specific assets of Hub; (b) the business scale of cross-border e-commerce is negatively related to the fuel cost of railway transportation; (c) the business scale of cross-border ecommerce is positively related to the safety of railway transportation; (d) the business scale of cross-border ecommerce is positively related to the timeliness of railway transportation; (e) the business scale of cross-border ecommerce is negatively related to the labor cost of highway transportation.

\subsection{Varibales Selection And Data Sources}

$\Delta$ inc is the income of Hub's cross-border e-commerce customers after first-order difference. It is used to measure the business scale of cross-border e-commerce. As the first major multimodal transportation marketing company in the United States, Hub's intermodal transportation mode is directly related to its cross-border e-commerce customers. Therefore, this model takes the income of Hub's crossborder e-commerce customers as dependent variable. The data are from annual reports for Hub from 2006 to 2018.

$\Delta$ con is the number of containers owned by Hub after first-order difference. It is used to measure the number of special assets of Hub. The standard 53-foot container is a kind of special equipment for intermodal transportation, and the intermodal transportation logistics business must rely on containers to complete loading, unloading and transportation. Therefore, the number of containers owned by Hub is selected as one of the dependent variables. The data are from annual reports for Hub from 2006 to 2018.

$\Delta \mathrm{fr}$ is the fuel consumption rate of railway transportation after the first-order difference. It is used to measure the transportation cost of railway transportation. In the long-distance freight transportation entrusted by cross-border e-commerce, the fuel consumption rate of railway transportation is the main factor affecting the transportation cost. Therefore, this variable is selected as the index to measure the railway transportation cost, and the data are from the American Department of Transportation's database.

$\Delta \mathrm{ar}$ is the accident rate of railway transportation after the first-order difference. It is used to measure the safety of railway transportation. In the statistical database of American Department of Transportation, the indicators related to transportation safety include accident incidence rate, casualty rate, mortality rate, etc. However, the casualty rate and mortality rate are greatly affected by the major railway transportation accidents in that year, which are relatively exogenous. Therefore, only the accident incidence rate is selected as the index to measure the 
railway transportation safety, and the data are from the American Department of Transportation's database.

$\Delta \mathrm{tr}$ is the turnover rate of truck drivers after the firstorder difference. The high turnover rate of truck drivers is an important reason for Hub to change its logistics mode because railway transportation can alleviate the problem of high turnover rate of truck drivers. Due to the higher the turnover rate, Hub needs to pay more to keep the truck drivers. Therefore, this paper takes the turnover rate of truck drivers as an explanatory variable to measure the labor cost. The data come from American Trucking Association's database.

$\Delta \mathrm{fc}$ is the number of freight cars of UP after the firstorder difference. It is used to measure the timeliness of railway transportation. According to the relevant documents of UP, UP faces the problem of track congestion in freight yard. For every 100 freight cars cleaned by UP, UP can release 1 mile of freight yard track space and save $3 \%$ waiting time of freight car. Therefore, the number of freight cars of UP is selected as an indicator to measure the timeliness of railway transportation. The data are from annual reports for UP from 2006 to 2018.

\section{Empirical Analysis And Results}

\subsection{Significance Test}

The data were imported into Eviews software. The results of multiple regression according to the above model are shown in Table 1. It can be found that: (a) at the significance level of 0.01 , the Prob. value of 0.00003 corresponding to $\mathrm{F}$ statistic is less than 0.01 , so the regression equation is significant; (b) at the significance level of 0.01 , the Prob. values corresponding to the four variables, $\Delta \mathrm{ar}, \Delta \mathrm{fc}$ and $\Delta \mathrm{tr}$ are all less than 0.01 , so the influence of $\Delta$ con, $\Delta \mathrm{ar}, \Delta \mathrm{fc}, \Delta \operatorname{tr}$ on the explained variable $\Delta$ inc is significant; the prob. Value 0.01480 corresponding to $\Delta \mathrm{fr}$ is greater than 0.01 , but less than 0.05 so at the significance level 0.05 , the influence of $\Delta$ ar on $\Delta$ inc is also significant. In summary, it can be considered that both the whole equation and independent variables have passed the significance test.

Table1. MULTIPLE REGRESSION RESULTS

\begin{tabular}{|c|c|c|c|c|}
\hline Variable & Coefficient & Std. Error & t-Statistic & Prob. \\
\hline $\mathbf{C}$ & -27.78945 & 1.55607 & -17.85873 & 0.00230 \\
\hline$\Delta \mathbf{c o n}$ & 17.46864 & 1.86980 & 9.34252 & 0.00590 \\
\hline$\Delta \mathbf{f r}$ & -156.34534 & 55.05971 & -2.83956 & 0.01480 \\
\hline$\Delta \mathbf{a r}$ & -65.97625 & 8.97219 & -7.35342 & 0.00710 \\
\hline$\Delta \mathbf{f c}$ & -8.83736 & 0.72746 & -12.14830 & 0.00410 \\
\hline$\Delta \mathbf{t r}$ & -11.75982 & 1.33041 & -8.83924 & 0.00680 \\
\hline R-squared & 0.93565 & Mean dependent var & 18.48025 \\
\hline Adjusted R-squared & 0.89354 & S.D. dependent var & 5.47805 \\
\hline S.E. of regression & 1.85742 & Akaike info criterion & 5.34014 \\
\hline Sum squared resid & 24.96653 & \multicolumn{2}{|c|}{ Schwarz criterion } & 5.20047 \\
\hline Log likelihood & -24.34438 & Hannan-Quinn criter. & 5.14367 \\
\hline F-statistic & 56.76659 & Durbin-Watson stat & 3.56051 \\
\hline Prob(F-statistic) & 0.00003 & \multicolumn{5}{l}{} \\
\hline
\end{tabular}

\subsection{Variable Correlation Test}

Table 2 shows the correlation coefficients between the explanatory variables $\Delta$ con, $\Delta \mathrm{fr}, \Delta \mathrm{fc}, \Delta \operatorname{tr}$ and $\Delta$ ar. Through the coefficients of the variables in the Table 2, we can find that there is no significant correlation among the variables in the model.

Table2. VARIABLE CORRELATION COFFICIENT MATRIX

\begin{tabular}{|c|c|c|c|c|c|}
\hline & $\Delta$ ar & $\Delta$ con & $\Delta$ fc & $\Delta$ fr & $\Delta$ tr \\
\hline$\Delta \mathbf{a r}$ & 1 & 0.273892 & 0.398206 & 0.355629 & 0.289279 \\
\hline$\Delta$ con & 0.273892 & 1 & 0.283965 & 0.258907 & 0.188897 \\
\hline$\Delta \mathbf{f c}$ & 0.398206 & 0.283965 & 1 & 0.180678 & 0.367826 \\
\hline$\Delta \mathbf{f r}$ & 0.355629 & 0.258907 & 0.180678 & 1 & 0.273857 \\
\hline$\Delta \mathbf{t r}$ & 0.289279 & 0.188897 & 0.367826 & 0.273857 & 1 \\
\hline
\end{tabular}

\subsection{Stability Test}

The data used in the model are all time series data. Therefore, unit root test is carried out for dependent variable $\Delta \mathrm{inc}$ and all independent variables $\Delta \mathrm{con}, \Delta \mathrm{fr}, \Delta \mathrm{fc}$, $\Delta \operatorname{tr}$ and $\Delta$ ar. The results of ADF test are shown in Table 3. The t-Statistics corresponding to the dependent variable $\Delta$ inc and the independent variables $\Delta$ con and $\Delta$ ar are $2.014563,-2.678972,-2.276397$ respectively, which are greater than the critical value at the significance level of 0.01 , but these three variables are stable at the significance level of 0.05 . The t-Statistics corresponding to the dependent variables $\Delta \mathrm{fr}, \Delta \mathrm{fc}$ and $\Delta \mathrm{tr}$ are $\quad-2.934563$, 4.478356 and -3.951846 respectively, which are all lower than the critical value at the significance level of 0.01 . In summary, there are three variables which are unstable at the significance level of 0.01 . However, if the significance level is reduced, all variables will pass the significance test at the significance level of 0.05 .

Table3. ADF TEST RESUlTS

\begin{tabular}{|c|c|c|c|}
\hline \multirow{2}{*}{ Variable } & \multicolumn{3}{|c|}{ Augmented Dickey-Fuller test statistic } \\
\cline { 2 - 4 } & t-Statistic & Prob. & $\begin{array}{c}\text { Test critical } \\
\text { values }\end{array}$ \\
\hline$\Delta$ inc & -2.014563 & 0.0351 & $\mathbf{1 \% \text { level }}$ \\
\hline$\Delta$ con & -2.678972 & 0.0189 & -2.754993 \\
\hline$\Delta$ fr & -2.934563 & 0.0057 & $\mathbf{5 \%}$ level \\
\hline$\Delta$ ar & -2.276397 & 0.0264 & -1.970978 \\
\hline$\Delta$ fc & -4.478356 & 0.0002 & $\mathbf{1 0 \%}$ level \\
\hline$\Delta$ tr & -3.951846 & 0.0005 & -1.603693 \\
\hline
\end{tabular}

\subsection{Regression Analysis}

When the significance test, variable correlation test and stability test of the model are all passed, the following parameter estimation equation can be written according to the regression results:

$\Delta i n c=-27.79+17.47 \Delta$ con $-156.35 \Delta f r-$ 65.98 $\Delta a r-8.84 \Delta t r-11.76 \Delta f c$

The results show that the number of containers owned by Hub, the fuel consumption rate of railway transportation, the accident rate of railway transportation accidents, the turnover rate of truck drivers and the 
number of freight cars of UP have significant impact on the income of Hub's cross-border e-commerce customers. Among them, the number of containers owned by Hub is significantly positively correlated with the income of Hub's cross-border e-commerce customers. But the other independent variables, the fuel consumption rate of railway transportation, the turnover rate of truck drivers, the number of freight trains of up company, and the accident rate of railway transportation, have a significant negative correlation with the income of Hub's cross-border e-commerce customers.

\section{Conlusions And Suggestions}

In order to study the impact of intermodal-transportation logistics mode on the scale of cross-border e-commerce companies, this paper selects the relevant data of Hub, and makes multiple regression analysis, and draws the following conclusion: the intermodal-transportation logistics mode of highway and railway collaborative transportation is conducive to the expansion of crossborder e-commerce business scale. There are many possible reasons for this. First of all, domestic logistics, which mainly relies on road transportation, not only leads to high fuel costs, but also increases the indirect costs brought by environmental pollution. In addition, longdistance highway transportation often requires at least two truck drivers to drive in turn to ensure the timeliness of transportation, and the truck drivers need to work away from home for several days. Such working characteristics also lead to higher labor cost of highway transportation. What's more, accidents of road transportation occur frequently. Logistics companies not only need to deal with the problem of compensation for cargo damage, but also need to pay a high rate of insurance premium to avoid risks. Therefore, the long-distance transportation of cargo is carried by railway, and the highway transportation only undertakes the short-distance link from the factory warehouse to the railway freight station, which can effectively reduce the domestic logistics cost of crossborder e-commerce companies and improve the price advantage of products.

In China, where the railway network is huge, the advantages of railway freight transportation have not been fully utilized. Road transportation is still the main mode in domestic link of cross-border e-commerce companies, which also explains the reason why the logistics cost of cross-border e-commerce companies in China is higher than that of the international average level. In order to solve this problem, the Chinese government, logistics companies and cross-border e-commerce companies should fully explore the feasibility and operability of multimodal transport logistics mode, and fully release the potential of railway freight transportation.

Due to the limited level of the author, there are still some deficiencies in this study. The successful example of cross-border e-commerce logistics mode in the United States is not limited to Hub studied in this paper. For example, in the domestic logistics service mode provided by UPS for cross-border e-commerce companies, UPS has strong land transportation and air transportation capacity resources, and its logistics mode is different from Hub. In the logistics mode of J.B. Hunt, another multimodal transport service provider in the United States, there is an important feature that J.B. Hunt and railway companies share the benefits and risks. The case of Hub in this paper cannot fully summarize and explain all the characteristics of cross-border e-commerce logistics mode in the United States. Therefore, if there are other scholars who want to carry out further research on the relevant issues of this paper, they can analyze the impact of different factors of cross-border e-commerce's domestic logistics mode on the business scale by studying other classic cases; they can also explore the relationship between the logistics mode and business scale of cross-border e-commerce companies from the overall grasp of the industry.

\section{Acknowledgment}

The inspiration of this paper comes from my further thinking when I studied intermodal transportation of America with the leading of my tutor, Tan Kehu. I would like to thank my tutor for his guidance over the past year and I also want to thank my friend, Ma Yuzhou, who encouraged and helped me a lot when I was in trouble.

\section{References}

1. Zhang Xiaheng, Ma Tianshan. Dilemma and Countermeasures of cross border e-commerce logistics in China [J]. Contemporary economic management, 2015,37 (5): 51-54. (in Chinese)

2. Huang Jingxian. Research on the development status of international express industry $[\mathrm{J}]$. E-commerce, 2018 (6): $31+58$. (in Chinese)

3. Wu Shuping, Yu Baoqin. Research on collaborative development path of e-commerce and express logistics [J]. Management review, 2016,28 (7): 93101. (in Chinese)

4. Li Deku. Logistics management innovation in ecommerce environment [J]. China circulation economy, 2013,27 (8): 39-43. (in Chinese)

5. Zhang Xiaheng, Guo Hailing. Cross border ecommerce and cross-border logistics synergy: mechanism and path $[\mathrm{J}]$. China circulation economy, 2016,30 (11): 83-92. (in Chinese)

6. Fan Jing, Yuan Bin. Experience and Enlightenment of foreign cross-border e-commerce logistics mode innovation $[\mathrm{J}]$. Business economics research, 2016 (11): 133-135. (in Chinese)

7. He Jiang, Qian Huimin. Research on collaborative strategy of cross border e-commerce and cross-border logistics [J]. Logistics technology, 2017,40 (7): 1-6. (in Chinese)

8. Guido, Daniel W. Railroads Asset Sales Shift Burden to Fleets[J]. Transport Topics. 2005. No.3668,pp.1,10.

9. Benjamin Klein, Robert G. Crawford and Armen A. Alchian. Vertical integration, appropriable rents, and the competitive contracting process[J]. Journal of Law and Economics. 1978. Vol.21(2):297-326. 